\title{
POSITIVITY AND DEMOGRAPHIC ASSOCIATIONS OF ANTINUCLEAR TEST IN A LARGE CONSECUTIVE SERUM SAMPLES REFERRED FOR AUTOANTIBODIES TESTING
}

\author{
Leandro Kegler Nardes ${ }^{1}$, Wilton Ferreira Silva Santos ${ }^{2, \star}$, Daniele de Castro Félix² \\ 1.Escola Superior de Ciências da Saúde, Brasília (DF), Brazil; 2. Sabin Medicina Diagnóstica, Brasília (DF), Brazil. \\ *Corresponding author: wiltonss@uol.com.br
}

\section{BACKGROUND}

Autoantibodies to cellular constituents are the hallmark of autoimmunity. Antinuclear antibodies (ANA) are the most frequent autoantibodies seen in autoimmune diseases. Prevalence of ANA increase with age and is higher in women than in men. The objective was to determine the prevalence of ANA and the differences of positivity according to gender and age in a large consecutive serum sample.

\section{METHODS}

We conducted a retrospective analysis of routine ANA testing, carried out by indirect immunofluorescence on HEp-2 cells, according to manufacturer's instructions. Visual reading of the HEp-2 slides was performed according to the V Brazilian Consensus on Autoantibodies. Titers $\geq 1 / 80$ were referred as positive. Positivity according to gender and age of the patients included were compared.

\section{RESULTS}

Between January and June of $2017,54,990$ serum samples were referred to the laboratory for autoantibodies testing. From these, $20.9 \%(11,478)$ were positive at titer $\geq 1 / 80$ and $79.1 \%(43,512)$ were negative. The median age of the patients was 43 years old (mean and $S D=41 \pm 17$ years). According to age, the patients were separated in four groups: $0-19(n=4,800) ; 20-39(n=20,971) ; 40-59$ $(n=19,767)$ e $\geq 60(n=9,452)$. The proportion of positive results in these groups was $23.3^{*}, 20.2,20.1$ and $22.8^{*} \%$, respectively. A higher positivity of the test was observed in the ranges of $0-19$ and 60 years $(p<0.0001)$. Out of 40,842 of the 54,990 patients were women (74.3\%). ANA positive results were observed in 11,478 of the participants. From these, $85.1 \%$ was from the feminine gender. We observed a significant difference in ANA positivity between women ( $24 \%)$ and men ( $12 \%(p<0.0001)$. The highest positivity of ANA tests in women compared to men was significant in any of the age groups studied.

\section{CONCLUSION}

ANA test positivity on HEp-2 cells was observed in about one fifth of the samples referred to the laboratory for autoantibodies detection. The age groups where ANA tests were more positive were $0-19$ and $\geq 60$ years. When compared to men, the ANA positivity in women was higher whatever the age group analyzed.

\section{KEYWORDS}

Antinuclear antibodies, Autoantibodies, ANA test, Laboratory diagnosis, Autoimmunity. 